\title{
Synthesis and Characterisation of Polyester Resin Matrix Composites Reinforced with Pineapple Leaf Micro Particles
}

\author{
Stephen Durowaye ${ }^{1}$, Olatunde Sekunowo, Catherine Kuforiji, Ganiyu Lawal, Jacob Okon \\ Department of Metallurgical and Materials Engineering, University of Lagos, Nigeria \\ ${ }^{1}$ Corresponding author: sdurowaye@unilag.edu.ng
}

Received: Sep 24, $2018 \quad$ Revised: $\operatorname{Jan} 25,2019 \quad$ Accepted: Jan 28, 2019

\begin{abstract}
Reinforcement of polymers with particles to enhance their mechanical properties for various applications cannot be over emphasized. Hence, the microstructure and mechanical behaviour of polyester resin matrix composites reinforced with pineapple leaf particles was studied in order to develop an engineering material for industrial applications. Pineapple leaf particles treated and untreated with $\mathrm{NaOH}$ were separately blended with unsaturated polyester resin. $1 \mathrm{~g}$ of catalyst and $0.5 \mathrm{~g}$ of accelerator were added to the mixture to achieve a homogeneous interfacial interaction. The composites were made by mould casting and their microstructure and mechanical properties were evaluated. The $\mathrm{NaOH}$ treated pineapple leaf particles reinforced composite exhibited the highest tensile strength of $98.73 \mathrm{MPa}$ at $15 \mathrm{wt}$. \% and impact energy of $20.73 \mathrm{~J}$ at $20 \mathrm{wt}$. $\%$. Microstructure showed a fairly uniform distribution of the pineapple leaf particles in the polyester resin matrix coupled with the strong interfacial bonding of the filler and matrix as the major factors responsible for the enhancement of the tensile strength and impact energy of the composites.
\end{abstract}

Keywords: Polyester resin, pineapple leaf particles, tensile strength, impact energy

\section{Introduction}

In the middle of the $20^{\text {th }}$ century, there was an increase in the use of synthetic fibres. However, industries are now increasingly using plant fibres for processing and production of various materials for numerous applications. Increasing environmental awareness, new global agreements, governmental policies, and regulations have been the driving forces for plant based fibres as alternative reinforcement materials for polyester matrix composites due to their high specific strength, stiffness, and natural availability. As a result of the increasing environmental awareness, one of the important factors being considered in the recent development of high performance materials is ecological friendliness with minimum effect on environment by using renewable and recyclable resources. Consequently, researchers have been investigating these materials as potential fillers in polyester composite system. Fibre-reinforced structural plastics are taking the central stage in almost every sphere of materials science. Ligno cellulosic natural fibres like the pineapple leaf fibre come as a viable and abundant substitute for the expensive and non-renewable synthetic fibres. These fibres with high specific strength improve the mechanical properties of the polymer matrix. In tropical countries, fibrous plants are available in abundance and some of them are agricultural crops of which pineapple is among. These fibres are multicellular and ligno 
cellulosic. They are extracted from the leaves of the plant (Ananas comosus) belonging to the Bromeliaceae family. Among the various natural fibres, pineapple leaf fibres (PALFs) exhibit excellent mechanical properties. The main chemical constituents of pineapple fibre are cellulose (70-82 \%), lignin (5-12\%), and ash (1.1\%) [3]. The superior mechanical properties of pineapple fibre are associated with its high cellulose content and comparatively low micro fibrillar angle. The performance of fibre reinforced environmentally friendly materials depends on the development of coherent interfacial bonding between the fibres and the matrix [3]. Pineapple leaf fibres at present are waste products of pineapple cultivation. Interestingly, pineapple leaf particles can be obtained from the fibre by drying, grinding and sieving without much cost input for industrial use.

Among matrix resins, unsaturated polyesters have been commonly used for making thermoset composites, especially with glass fibres. Natural fibres like jute, coir, sisal, sun hemp, straw, etc. are incorporated into the polyester matrix to make composites. Unsaturated polyesters are extremely versatile in properties and applications and have been popular thermoset used as polymer matrix in composites [5]. Furthermore, polyester composite is relatively easy to prepare based on the existing technology with a balanced set of properties as required. Researchers have found out that with some modifications, these materials can exhibit excellent performance especially in strength and stiffness [4]. Hence, the need for the development and characterization of polyester resin matrix composites reinforced with various fillers, especially natural fillers such as pineapple leaf particles for application in many areas.

\section{Materials and Methods}

\subsection{Materials}

The materials used are pineapple leaf (palf), unsaturated polyester resin, mould release agent, accelerator (Cobalt Naphthanate), and catalyst (methyl ethyl ketone peroxide). The pictures of some of these materials are shown in Figs. 1 and 2 and the composition of the unsaturated polyester resin is shown in Table 1.

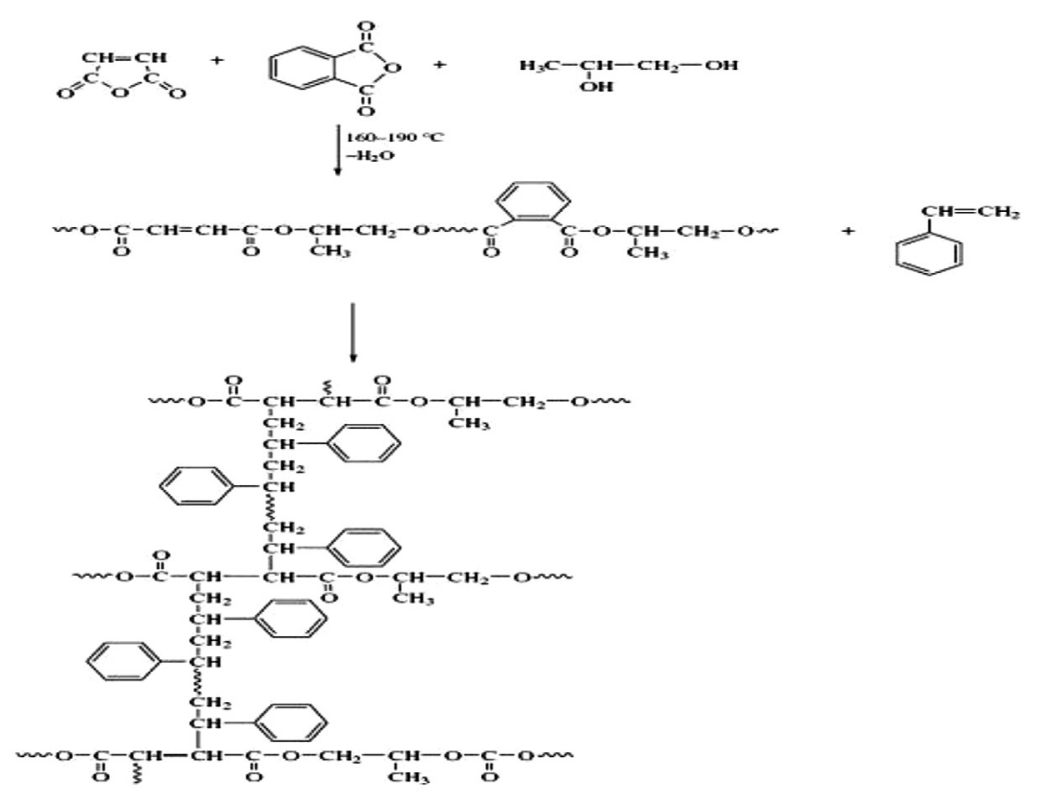

Fig. 1: Chemical structure of a typical unsaturated polyester resin linkage [2] 


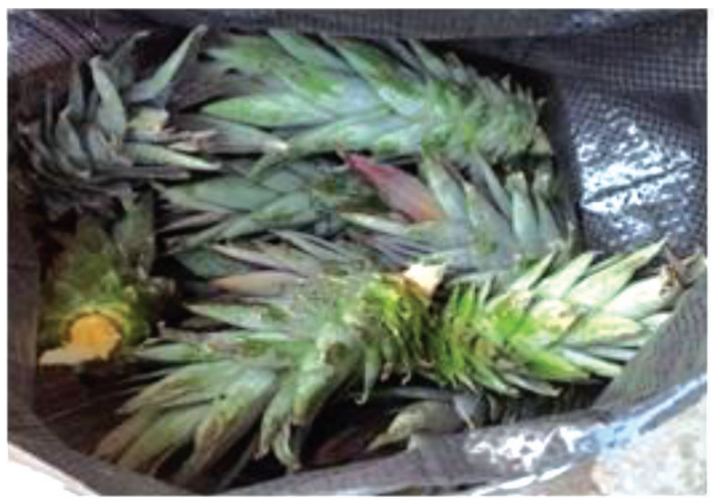

(a)

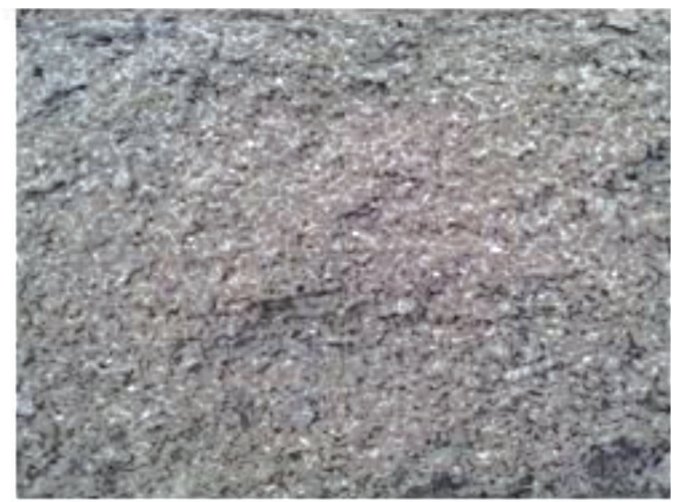

(b)

Fig. 2: (a) Pineapple leaf (b) Pineapple leaf particles

Table 1: Composition of unsaturated polyester resin

\begin{tabular}{lccccc}
\hline Materials & $\begin{array}{l}\text { Propylene } \\
\text { glycol }\end{array}$ & $\begin{array}{l}\text { Phythalic } \\
\text { anhydride }\end{array}$ & $\begin{array}{l}\text { Maleic } \\
\text { anhydride }\end{array}$ & $\begin{array}{l}\text { Styrene } \\
\text { monomer }\end{array}$ & $\begin{array}{l}\text { Additive/ } \\
\text { Pigment } \\
\text { paste }\end{array}$ \\
\hline Weight (\%) & 23 & 21 & 16 & 38 & 2 \\
\hline
\end{tabular}

\subsection{Treatment with $\mathrm{NaOH}$}

$40 \mathrm{~g}$ of $\mathrm{NaOH}$ pellets was dissolved in $1000 \mathrm{~cm}^{3}$ distilled water to make $1 \mathrm{M} \mathrm{NaOH}$ and the pineapple leaf particles were soaked in the $1 \mathrm{M} \mathrm{NaOH}$ solution for 20 minutes. The leaves were then washed in distilled water to remove the dirt and dried in the sun $\left(34^{\circ} \mathrm{C}\right)$ for one day to remove residual moisture. This is basically for surface modification of the pineapple leaves. They were torn to small pieces manually, ground into particles using a grinding machine and sieved to $150 \mu \mathrm{m}$ sizes. The sieved pineapple leaves particles shown in Fig. 2 was used as reinforcement.

\subsection{Samples Production}

Appropriate quantity of reinforcement (150 $\mu$ m pineapple leaf particles) was added to the matrix (polyester resin). The mixture was manually stirred with a glass rod until a good mixture was obtained. Thereafter, $1 \mathrm{~g}$ of catalyst and $0.5 \mathrm{~g}$ of accelerator were added to each mixture and was thoroughly stirred. $80 \mathrm{~g}$ of each mixture (polyester resin and pineapple leaf particles) was poured into a wooden mould coated with paper tape which acted as poly vinyl alcohol (PVA) and allowed to cure. After curing, the specimens were stripped from the mould. This procedure was repeated for all specimens produced with changes in the weight percentage as shown in Table 2. The same procedure was used in producing specimens not treated with $\mathrm{NaOH}$.

\subsection{Microstructural Determination}

The specimens were etched with a solution of $\mathrm{HF}$ and $\mathrm{HNO}_{3}$ in volume ratio 1:12 at room temperature for $10 \mathrm{~s}$ and then examined using an optical metallurgical microscope (model CETI 0703552; Medline Scientific Limited, Oxfordshire UK). 


\subsection{Flexural Strength Determination}

Three-point flexural testing were conducted using testometric testing machine with serial number 25257 and capacity $25 \mathrm{KN}$. The flexural test was carried according to ASTM D 7264 at a cross-head speed of $20 \mathrm{~mm} / \mathrm{min}$, maintaining a span of $100 \mathrm{~mm}$. This test was conducted at room temperature on specimens of dimension $120 \times 50 \times 10 \mathrm{~mm}$. The testometric machine was used to carry out the three point bending flexural test on the polymeric composites at $0,5,10,15,20$, and $25 \mathrm{wt}$. $\%$ filler content.

Table 2: Materials formulation

\begin{tabular}{|c|c|c|c|}
\hline $\begin{array}{c}\text { Reinforcement } \\
(\mathbf{1 5 0} \boldsymbol{\mu m} \text { Pineapple leaf particles) }\end{array}$ & \multicolumn{2}{c|}{$\begin{array}{c}\text { Matrix } \\
\text { (Polyester resin) }\end{array}$} \\
\hline Weight $(\%)$ & Weight $(\mathrm{g})$ & Weight $(\%)$ & Weight $(\mathrm{g})$ \\
\hline $0($ Control $)$ & 0 & 100 & 80 \\
\hline 5 & 4 & 95 & 76 \\
\hline 10 & 8 & 90 & 72 \\
\hline 15 & 12 & 85 & 68 \\
\hline 20 & 16 & 80 & 64 \\
\hline 25 & 20 & 75 & 60 \\
\hline
\end{tabular}

\subsection{Hardness Determination}

Evaluation of the specimens' hardness was carried out in accordance with ASTM D 785 standard using a Brinell hardness machine with ball indenter of diameter $20 \mathrm{~mm}$ and maximum load of $4000 \mathrm{~N}$. Each of the specimens of dimension $25 \mathrm{~mm} \times 25 \mathrm{~mm} \times 10 \mathrm{~mm}$ was mounted on the machine and a load of $10 \mathrm{~kg}$ was applied for about 15 seconds and the diameter of indentation left in the specimen was measured with a low powered microscope. The Brinell harness number was calculated by dividing the load applied by the surface area of the indentation. In order to eliminate possible segregation effect, a minimum of three hardness readings were taken for each specimen at different locations. The specimens' Brinell hardness values were computed using the expression:

$$
\text { Hardness }(\mathrm{HBN})=\frac{2 \mathrm{P}}{\pi \mathrm{D}\left[\mathrm{D}-\sqrt{\mathrm{D}^{2}-\mathrm{d}^{2}}\right]}
$$

where $\mathrm{P}$ is load $(\mathrm{kg}), \mathrm{D}$ is diameter of indenter $(\mathrm{mm}), \mathrm{d}$ is diameter of indentation $(\mathrm{mm})$, and $\pi=3.142$.

\subsection{Tensile Strength Determination}

The tensile test specimens were prepared using QualiLathe-210-CNC lathe machine. The test was conducted on the specimens using an Instron universal testing machine in accordance with the American Standard testing and measurement method D412 (ASTM D412 1983) using dumbbell test piece. The machine was operated at a cross head speed of $10 \mathrm{~mm} / \mathrm{min}$. Each tensile specimen $(120 \mathrm{~mm} \times 80 \mathrm{~mm} \times 50 \mathrm{~mm}$ ) was positioned in the Instron universal tester and then subjected to tensile load as the specimen stretches and the computer generated graph as well as all the desired parameters until the specimen fractures. A graph of load versus extension was plotted automatically by the tester and various properties of the specimen determined are: tensile strength, tensile strain, modulus, and tensile strain at break. 


\subsection{Impact Energy Determination}

This test was carried out on the specimens in accordance with ASTM D256 standard using an Izod impact tester. Each specimen of dimension $75 \mathrm{~mm}$ x $10 \mathrm{~mm}$ x $10 \mathrm{~mm}$ with a $2 \mathrm{~mm}$ deep V-notch at the center was clamped vertically with the notch facing the striker. The striking pendulum was allowed to swing downwards from a height of $1.3 \mathrm{~m}$ at a velocity of $5 \mathrm{~m} / \mathrm{s}$ impacting the specimen and the energy absorbed to fracture each specimen was read off from the instrument's dynamometer.

\section{Results and Discussion}

\subsection{Microstructure}

Figs. 3(a-d) show a fair distribution of the pineapple leaf particles in the microstructure of the composites which was the major factor responsible for the enhancement of the impact energy and tensile strength of the composites. Beyond 15 wt. \% reinforcement as shown in the micrographs of Figs. 3(e) and (f), there was agglomeration of the pineapple leaf particles in the composites which deteriorated their mechanical properties. The pineapple leaf particles being ligno-cellulosic in nature clung together. The strong inter-filler hydrogen bonding allowed them to cling together, thus resisting dispersion of the particles leading to weak interfacial bonding, small void spaces, and de-bonding in the resulting composites. These led to a reduction in the mechanical properties of the composites.

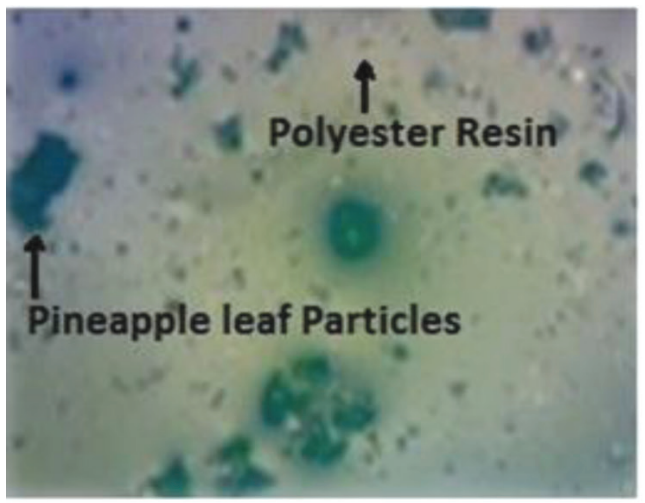

(a)

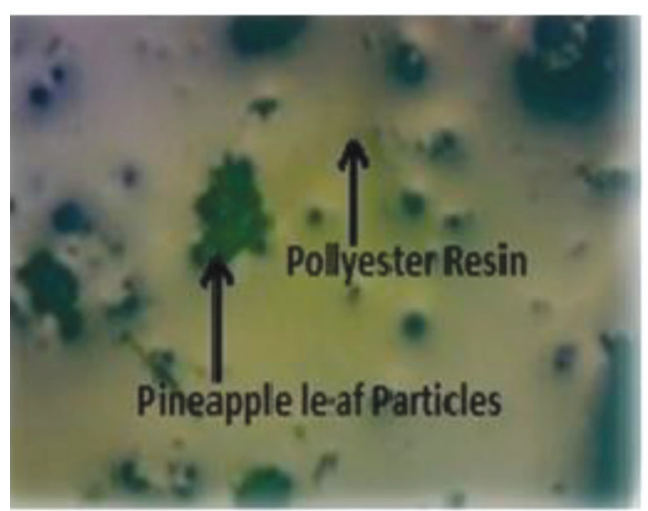

(c)

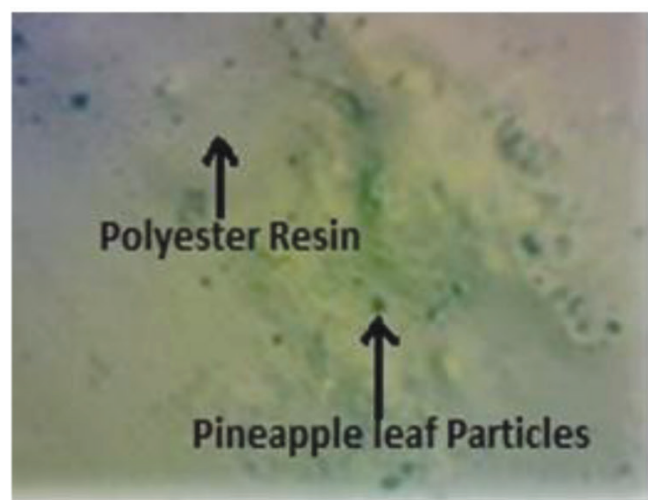

(b)

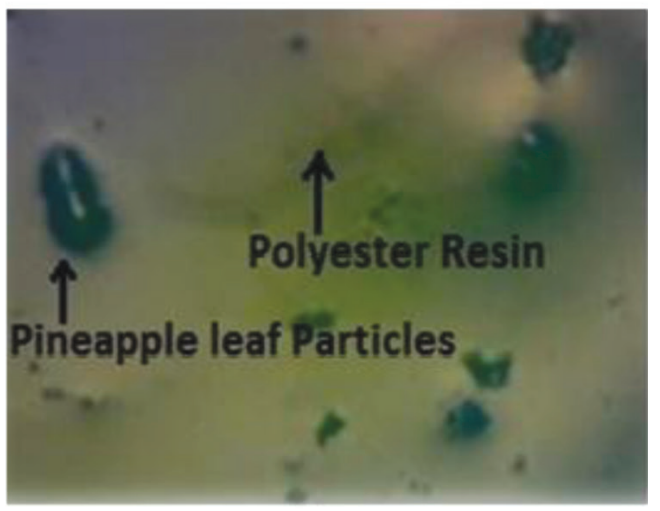

(d) 


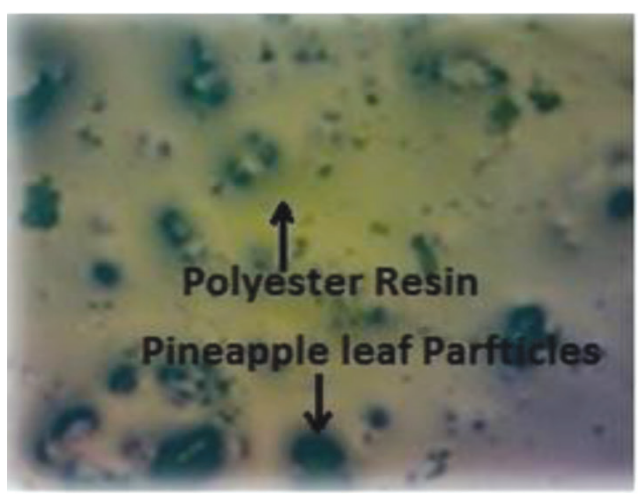

(e)

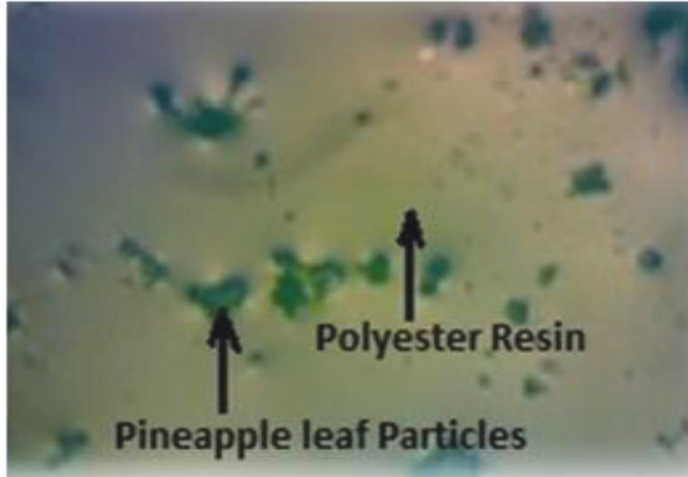

(f)

Fig. 3: Micrographs of (a) $5 \mathrm{wt. \%}$ untreated pineapple particles reinforced composite (b) 5 wt.\% treated pineapple particles reinforced composite (c) $15 \mathrm{wt} . \%$ untreated pineapple particles reinforced composite (d) $15 \mathrm{wt} . \%$ treated pineapple particles reinforced composite (e) $25 \mathrm{wt} . \%$ untreated pineapple particles reinforced composite (f) $25 \mathrm{wt} . \%$ untreated pineapple particles reinforced composite

\subsection{Flexural Strength and Modulus}

As illustrated in Fig. 4, pure polyester resin sample (0 wt. \%) exhibited the highest bending strength value of $35.04 \mathrm{MPa}$. This is because the matrix displayed more ductility than the reinforced specimens. The flexural properties of composites depend critically on the microstructure and the interfacial bonding between the reinforcement and the matrix [1]. The decrease in flexural strength was due to agglomerate formation in the microstructure as shown in Figs. $3 \mathrm{e}$ and $3 \mathrm{e}$ at higher concentrations of the reinforcement of the two composites which is also observed in the tensile behaviour. Reduction in bending strength at high reinforcement can also be attributed to controlled mobility of matrix by filler particles. As amount of reinforcement increased there was a reduction in the total surface area available for matrix-filler interaction.

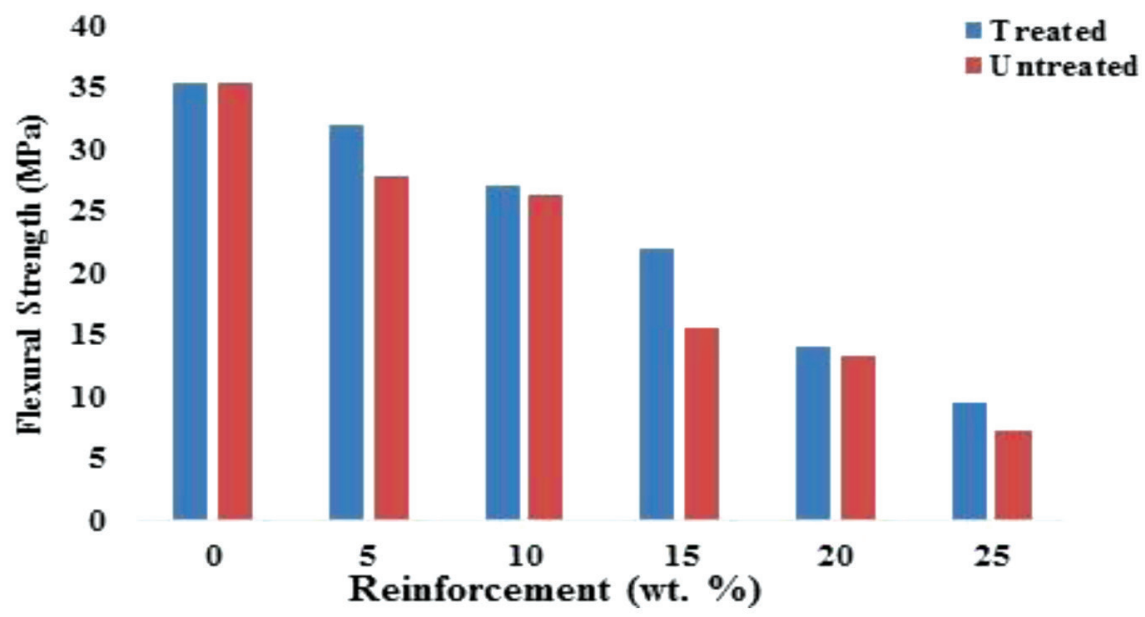

Fig. 4: Effect of varied reinforcement addition on flexural strength of the composites 


\subsection{Hardness}

The hardness value decreased with increasing reinforcement as shown in Fig. 5. The unreinforced polyester resin exhibited hardness value of $129.08 \mathrm{BHN}$ while the treated and untreated specimens exhibited hardness values of $103.12 \mathrm{BHN}$ and $101.36 \mathrm{BHN}$ respectively at $5 \mathrm{wt}$. \% reinforcement. The hardness of the treated and untreated composites decreased with increasing reinforcement due to poor inter facial bonding between the reinforcement and the matrix as a result of the agglomeration of the reinforcing particles in the matrix as shown in microstructure (Figs. 3e and 3f). However, the $\mathrm{NaOH}$ treated pineapple leaf particles reinforced composites exhibited higher hardness values than the untreated composites. Treatment with $\mathrm{NaOH}$ is mainly a surface activation process that led to the formation of rough surfaces which increased the interfacial bonding between the reinforcing particles and the unsaturated polyester resin matrix.

\subsection{Tensile Strength}

As shown in Fig. 6, the tensile strength of the composites increased as reinforcement increased from $0-15 \mathrm{wt}$. \% reinforcement with the $\mathrm{NaOH}$ treated pineapple leaf particles reinforced composite exhibiting the highest tensile strength of $98.73 \mathrm{MPa}$ at $15 \mathrm{wt}$ \%. This was due to the strong interfacial bonding of the filler and matrix. Beyond $15 \mathrm{wt}$ \% reinforcement, the tensile strength decreased probably due to poor inter facial bonding between the reinforcement and the matrix as a result of the agglomeration of the reinforcing particles in the matrix as shown in the microstructure (Figs. 3e and 3f). The poor stress transfer between the particle-matrix interface could also cause the reduction in the tensile properties of the composites.

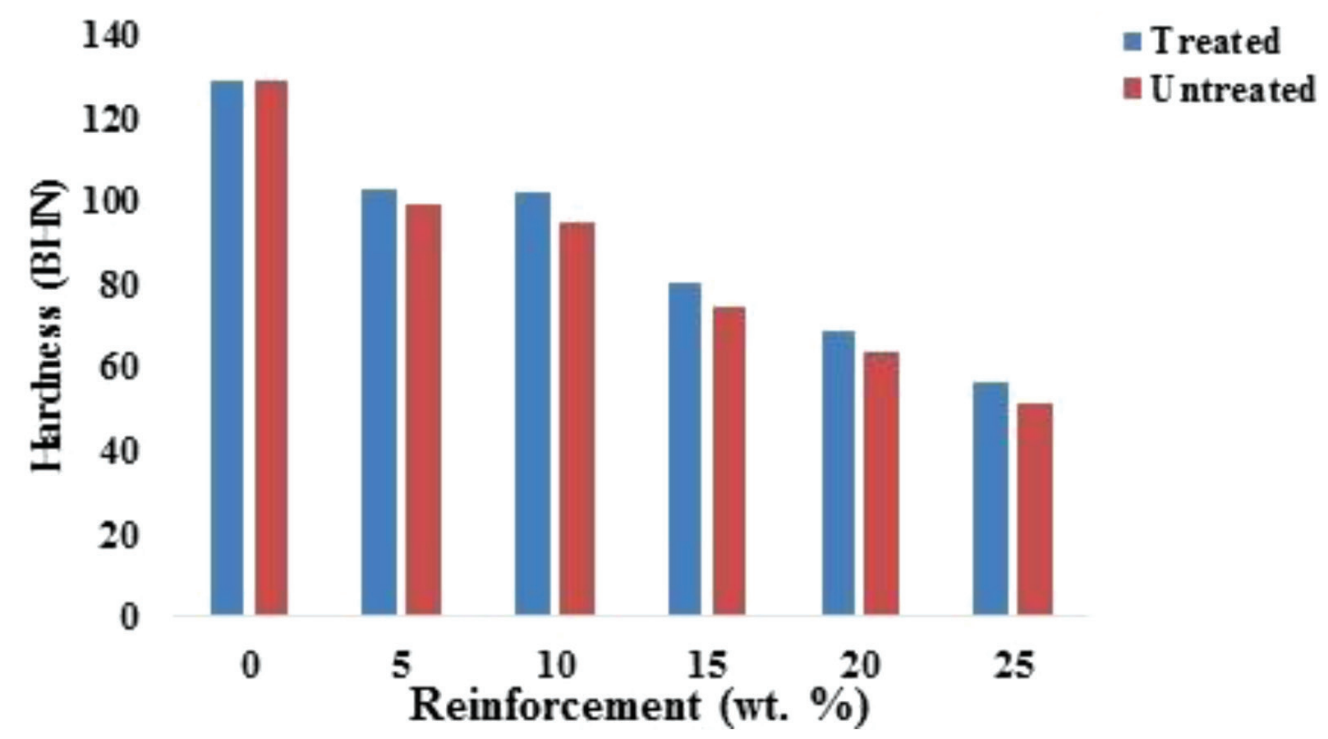

Fig. 5: Effect of varied reinforcement addition on hardness of the composites 


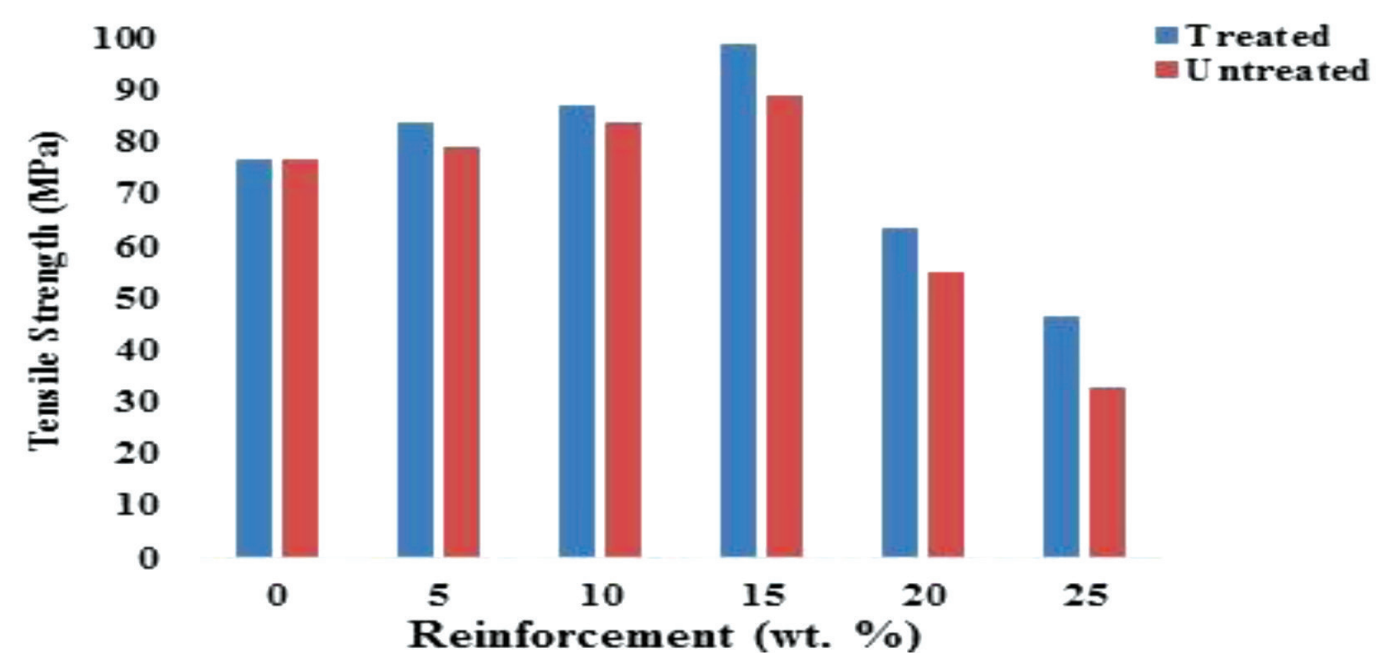

Fig. 6: Effect of varied reinforcement addition on tensile strength of the composite

\subsection{Impact Energy}

The impact energy of the composites increased as reinforcement increases from 0-20 wt. \% reinforcement with the $\mathrm{NaOH}$ treated pineapple leaf particles reinforced composite exhibiting the highest impact energy of $20.73 \mathrm{~J}$ as illustrated in Fig 7 . This was due to the strong interfacial bonding between the filler and matrix. Treatment with $\mathrm{NaOH}$ is mainly a surface activation process that led to the formation of rough surfaces which increased the interfacial bonding between the reinforcing particles and the unsaturated polyester resin matrix. Beyond $20 \mathrm{wt}$ \% reinforcement, the impact energy decreased which could be due to poor inter facial bonding between the reinforcement and the matrix as a result of the agglomeration of the reinforcing particles in the matrix as shown in the microstructure (Figs. 3e and 3f).

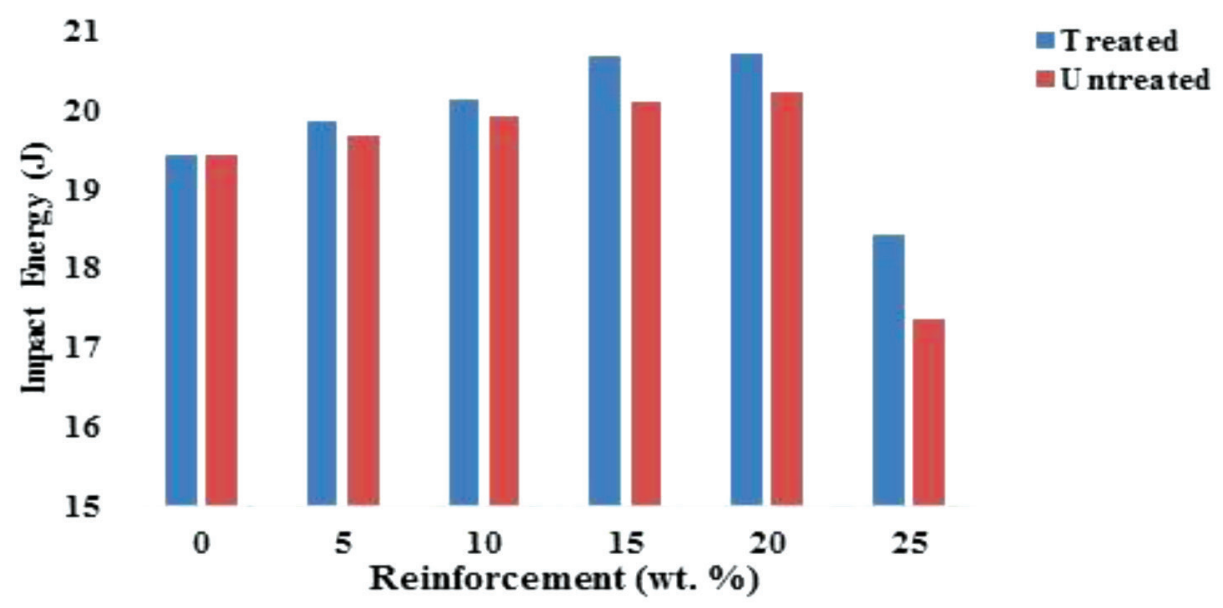

Fig. 7: Effect of varied reinforcement addition on impact energy of the composite 


\section{Conclusion}

Pineapple leaf particles reinforced unsaturated polyester resin matrix composites have been successfully synthesized and characterised. From the results of investigation and discussion thereof, the following conclusions can be made:

- $\mathrm{NaOH}$ treated pineapple leaf particles reinforced composite exhibited the highest tensile strength of $98.73 \mathrm{MPa}$ at $15 \mathrm{wt}$. \% and impact energy of $20.73 \mathrm{~J}$ at $20 \mathrm{wt}$. \%. This is due to the strong interfacial bonding of the filler and matrix.

- The $\mathrm{NaOH}$ treatment which is mainly a process of surface activation has contributed in enhancing the mechanical properties. The poor inter facial bonding between the reinforcement and the matrix as a result of the agglomeration of the reinforcing particles in the matrix as shown in microstructure (Fig. $3 \mathrm{~d}$ to $3 \mathrm{~g}$ ) was responsible for the reduction in the mechanical properties of the composites.

- Treated pineapple leaf particles reinforced unsaturated polyester resin composites can be used as suitable replacement for synthetic reinforced composites in the industries.

\section{References}

[1] Bhagat S and Verma PK (2013), Effect of graphite filler on mechanical behaviour of epoxy composite, International Journal of Engineering Technology and Advanced Engineering, 3: 427-430.

[2] Dholakiya BZ (2009), Use of non-traditional fillers to reduce flammability of polyester resin composites, Polimeri, $30: 10-17$.

[3] Gon D, Das K, Paul P and Maity S (2012), Jute composites as wood substitute, International Journal of Textile Science, $1: 84-93$.

[4] Sangthong S, Pongprayoon T and Yanumet N (2009), Mechanical property of improvement of unsaturated polyester composite reinforced with admicellar-treated sisal fibers, Elsevier, Composites: Part A, 40: 687-694.

[5] Syed-Azuan SA (2013), Effect of fiber volume fraction on tensile properties of rice husk reinforced polyester composites, Advances in Environmental Biology, 7: 1101-1104. 